\title{
ANALYTICAL INVESTIGATION OF SLAB BRIDGE DAMAGES CAUSED BY TSUNAMI FLOW
}

\author{
Keisuke Murakami ${ }^{1}$, Yoshiko Sakamoto ${ }^{2}$ and Tetsuya Nonaka ${ }^{3}$
}

\begin{abstract}
Tsunami caused by Tohoku earthquake in 2011 had brought fatal damages on many kinds of infrastructures such as ports, roads, bridges, lifelines and other important structures. Among those damages, we have found many bridges whose superstructure was flooded away by tsunami flow. This study proposes a composite simulation method in order to investigate the damage on bridges caused by tsunami action. The numerical method consists of a hydraulic analysis and a structural one. The proposed method is applied to the damaged bridge whose superstructure was flooded away by Tohoku earthquake tsunami. Based on the structural analysis, this study discusses the mechanism of damage caused by tsunami flow. Furthermore, this study confirms the validity of hydraulic analysis through physical experiment.
\end{abstract}

Keywords: tsunami; damage of bridge; Cadmas-Surf; EERC/Fiber

\section{INTRODUCTION}

Tsunami caused by Tohoku earthquake in 2011 had brought fatal damages on many kinds of infrastructures such as ports, roads, bridges, lifelines and other important structures. Among those damages, we have found many bridges whose superstructure was flooded away by tsunami flow. After Indonesian tsunami in 2004, damages of bridge caused by tsunami has been studied by many researchers (e.g. Araki et al. 2010, Nakao et al. 2010, Nii et al. 2009, 2010). Those studies have mainly investigated the response characteristic of bridge against tsunami attack through hydraulic experiment. On the other hand, interactions between tsunami and bridge include very complex phenomena, and an analytical approach based on a numerical simulation has been desired to understand the mechanism of structural damages.

This study proposes a composite simulation method in order to investigate the mechanism of damage on the superstructure of bridges caused by tsunami action. The numerical method consists of hydraulic analysis and structural one. The proposed method is applied to the damaged bridge whose superstructure was flooded away by Tohoku earthquake tsunami. Based on the structural analysis, this study discusses the mechanism of damage caused by tsunami flow. Furthermore, this study confirms the validity of hydraulic analysis through physical experiment.

\section{OUTLINE OF DAMAGED BRIDGE}

Fig. 1 shows some photos of flooded bridge which is investigated in this study. It was a concrete slab bridge, and the bridge was used as a bicycle path along the beach in Chiba prefecture. The bridge was constructed parallel to the highway bridge. The width of this bridge is $4.8 \mathrm{~m}$, its length is $19.1 \mathrm{~m}$, its height is $0.6 \mathrm{~m}$, and its weight is $1500 \mathrm{kN}$. The bottom face of the slab was flat. Water depth under the slab is about $1 \mathrm{~m}$ in normal condition, and the height of the slab above the water surface is $2.4 \mathrm{~m}$.

The Tohoku earthquake tsunami in 2011 flooded this slab bridge onto the adjacent highway bridge as shown in Fig.2. There were five anchor bars on both bearing section. It was found that the anchor bars of No.1 and No.2 were bended a little to the landward. On the other hand, other anchor bars from No.3 to No.5 stood upright without any deformations. From these damages of anchor bars, it was assumed that the slab of this bridge was lifted up due to tsunami at first. After this action, the tsunami force acting on the bottom of the slab increases during tsunami, and finally the slab was flooded onto the adjacent highway bridge with counterclockwise rotation.

\section{NUMERICAL SIMULATION OF TSUNAMI PROPAGATION}

The numerical simulation in this study comprises two parts. One is the hydraulic analysis and the other is the structural analysis. The hydraulic analysis, which solves the Navire-Stokes equation and continuity one with applying finite element method, provides the tsunami pressure distribution on the structure. This study employs CADMAS-SURF/3D (Coastal Development Institute of Technology 2010), which can solve fluid motion around a structure with arbitrary cross section in three dimensional spaces. This method employs VOF method to trace the free water surface.

\footnotetext{
${ }^{1}$ University of Miyazaki, 1-1 Gakuen Kibanadai-Nishi, Miyazaki, 889-2192, Japan

${ }^{2}$ Earthquake Engineering Research Center Inc., 1-1 Gakuen Kibanadai-Nishi, Miyazaki, 889-2155, Japan

${ }^{3}$ Earthquake Engineering Research Center Inc., 1-1 Gakuen Kibanadai-Nishi, Miyazaki, 889-2155, Japan
} 

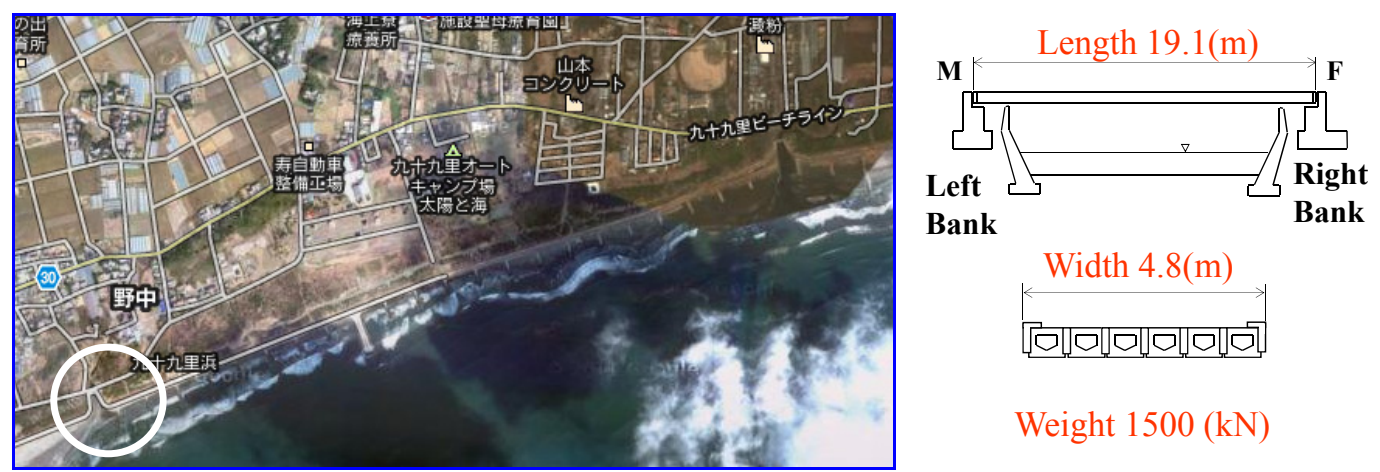

Weight $1500(\mathrm{kN})$
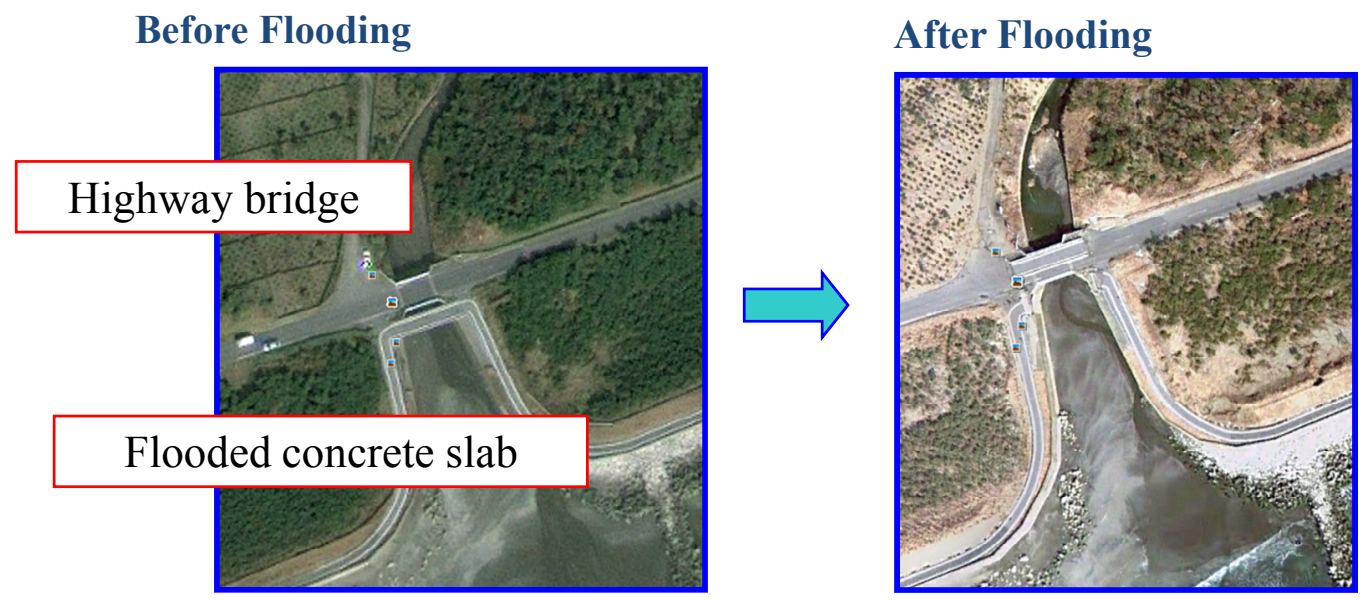

Figure 1. Aerial photos which was taken before and after the flooding of bridge.
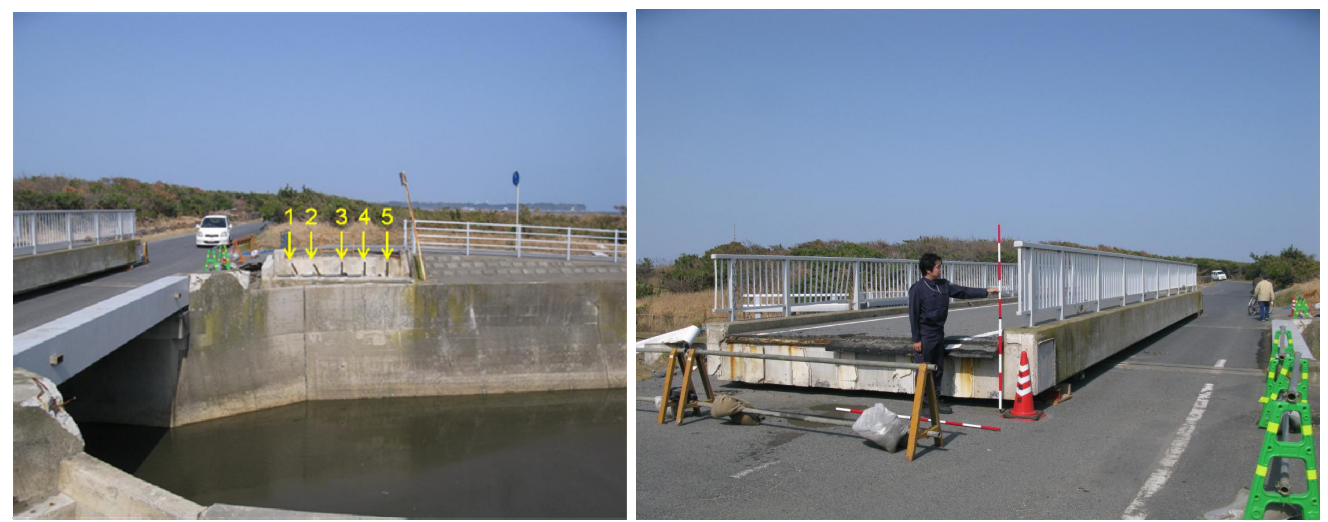

Figure 2. Right photo shows the flooded slab and left photo also shows the deformations of anchor bars.

Fig. 3 shows the numerical region and the dimension of model on $x-y$ and $x-z$ plane. Tsunami approaches the bridges from left hand side. Based on the field survey, the tsunami height on offshore of this coast was around $2.2 \mathrm{~m}$. As an input boundary condition, the time history of water surface elevation and velocity are needed to be applied on the left hand side of this numerical region. In this study, the time history of water surface elevation on input boundary was obtained from hydraulic experiment beforehand. A bore type tsunami with $20 \mathrm{~cm}$ in height was generated in the wave tank, and the water surface elevation was obtained as Fig.4 by following Froude similitude. The velocity profile was calculated from Eq. 1, which was proposed by Fukui (Fukui, et. al. 1961).

$$
U=\zeta \sqrt{\frac{g(H+h)}{2 H(H-\eta \zeta)}}
$$


where $U$ means depth averaged velocity, $H$ means total water depth under tsunami, $\eta$ means temporal water surface elevation, and $\zeta$ means a velocity coefficient.

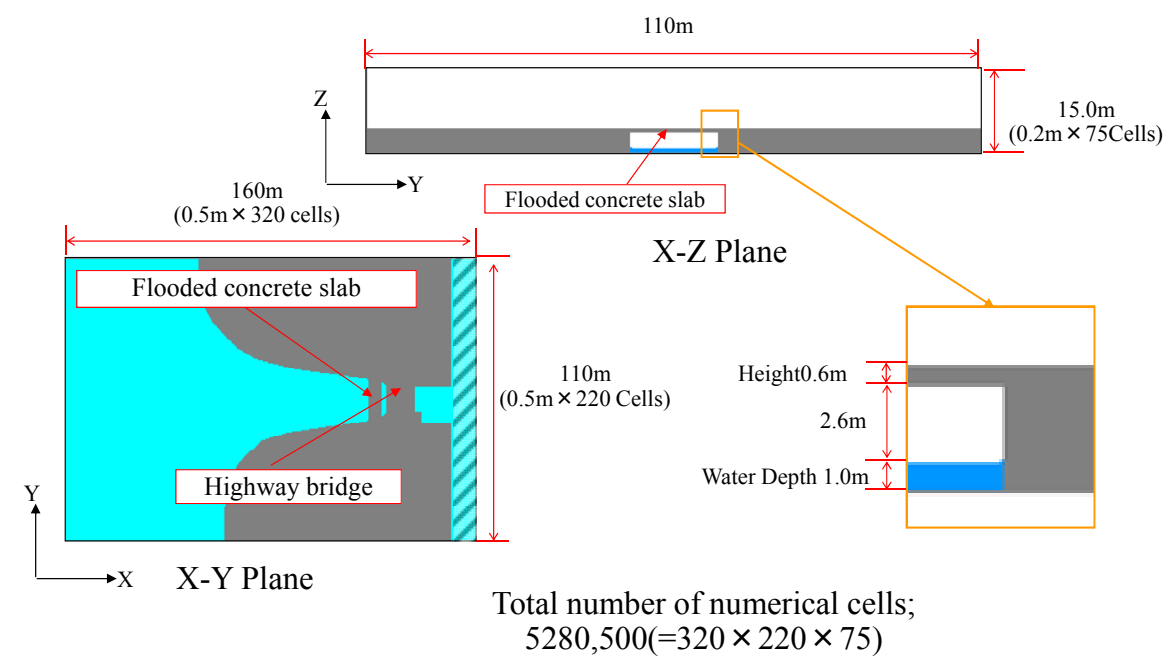

Figure 3. Numerical region and its dimension on $x-y$ and $x-z$ plane.

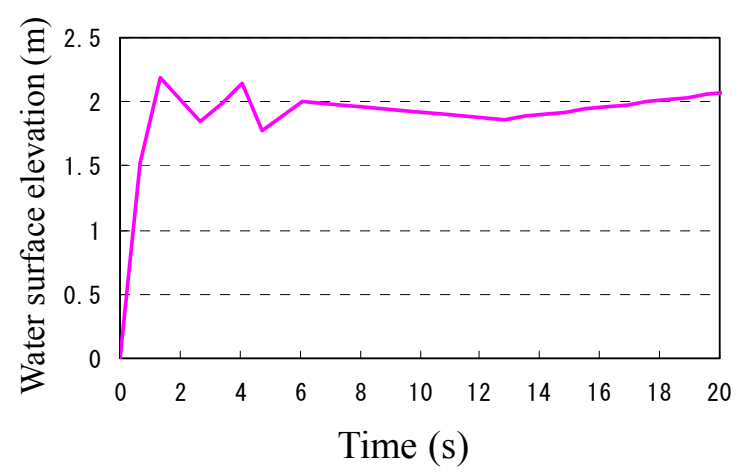

(a) Water surface elevation

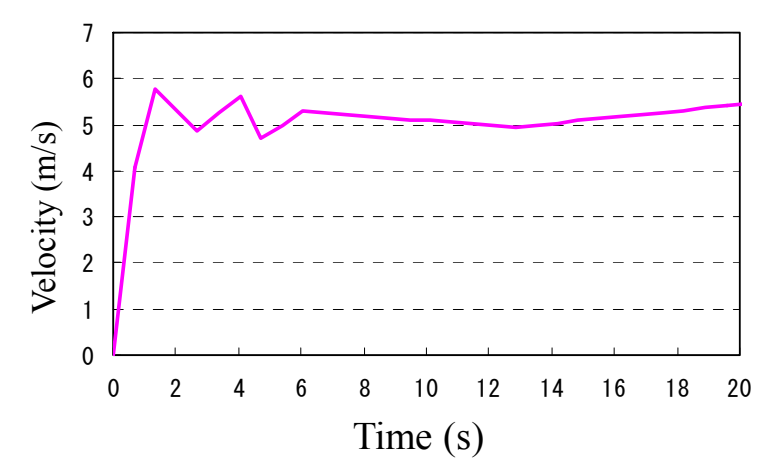

(b) Fluid velocity

Figure 4. Time history of water surface elevation and velocity applied on the input boundary.

Fig. 5 shows some snapshots of propagating tsunami in numerical wave tank. The tsunami height is around $2.2 \mathrm{~m}$ on offshore. The tsunami height gradually increases because the width of river mouth becomes narrow as shown in Fig.3. Fig.6 shows the tsunami height at A, B and C, where the locations are shown in this figure. The tsunami height reaches $5.5 \mathrm{~m}$ at the front and the rear of the flooded bridge, and the bridges are fully submerged under this condition. 

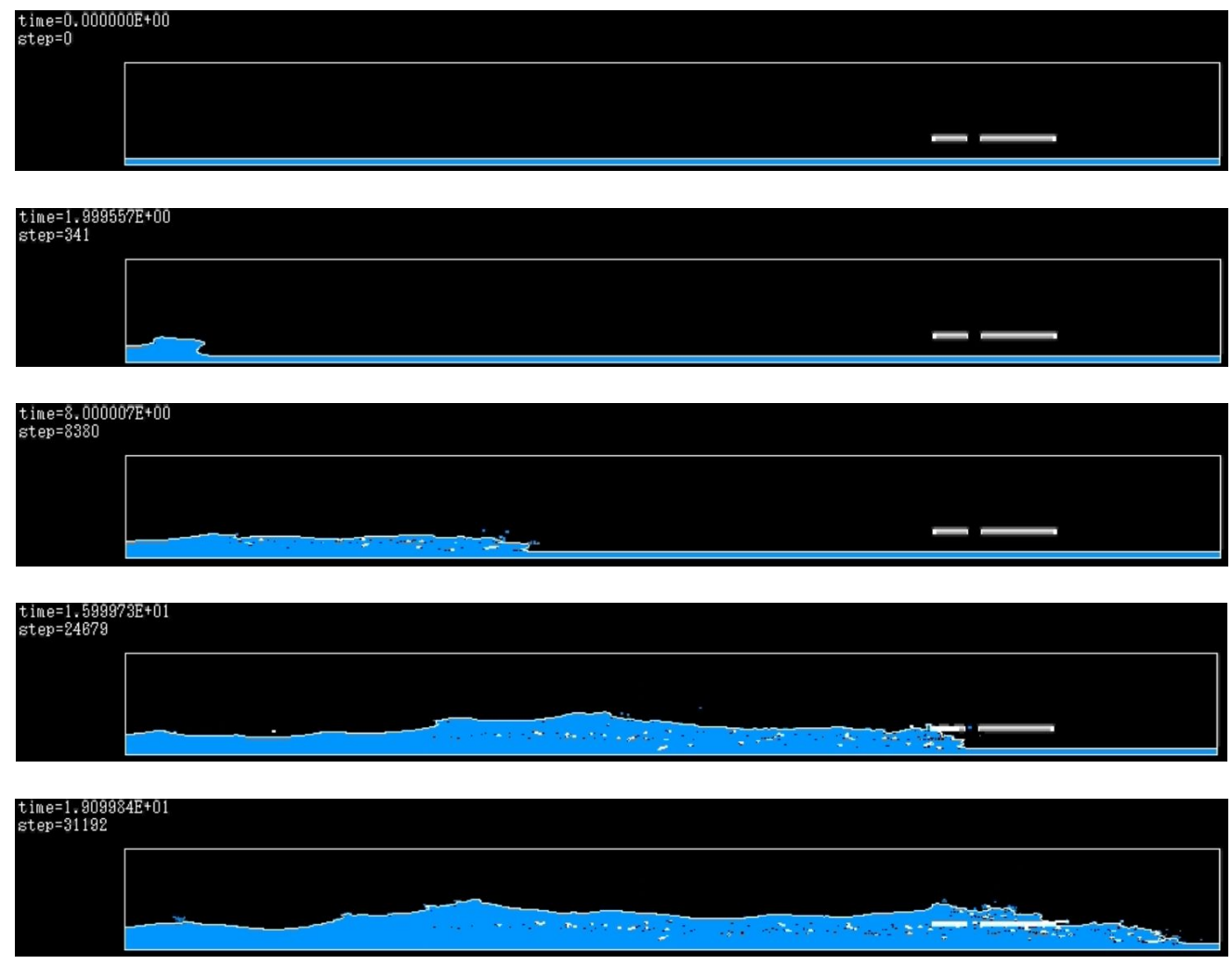

Figure 5. Snapshots of tsunami propagation in numerical wave tank.

Fig.7 shows the time history of tsunami pressure acting on the center of front, real, bottom and upper face of the slab. The positive pressure can be seen on each face. The difference of pressure between bottom and upper face play an important factor in discussing the stability of slab under tsunami action. An impulsive pressure due to tsunami attack can be seen on the front face. After the first tsunami impact, the pressure on the front face decreases once and gradually increases again due to the tsunami flow over the bridge.

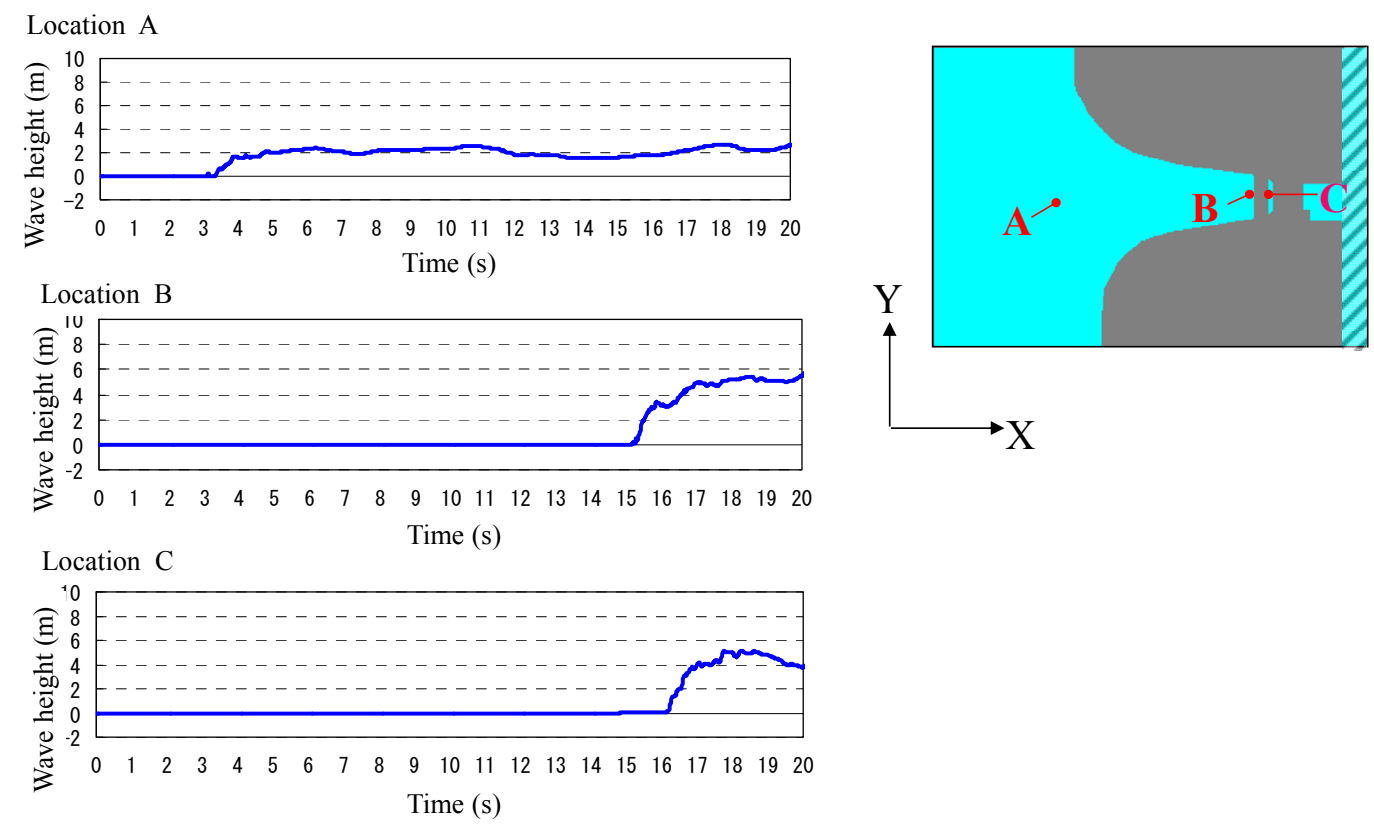

Figure 6. Time history of water surface elevation at the location A, B and C. 

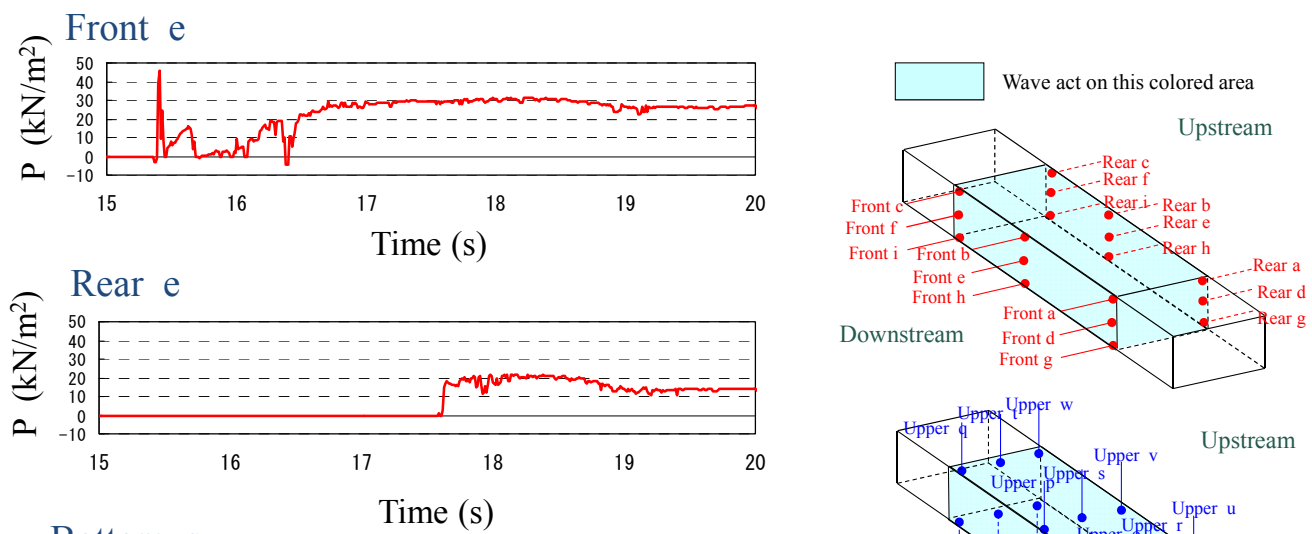

Bottom s
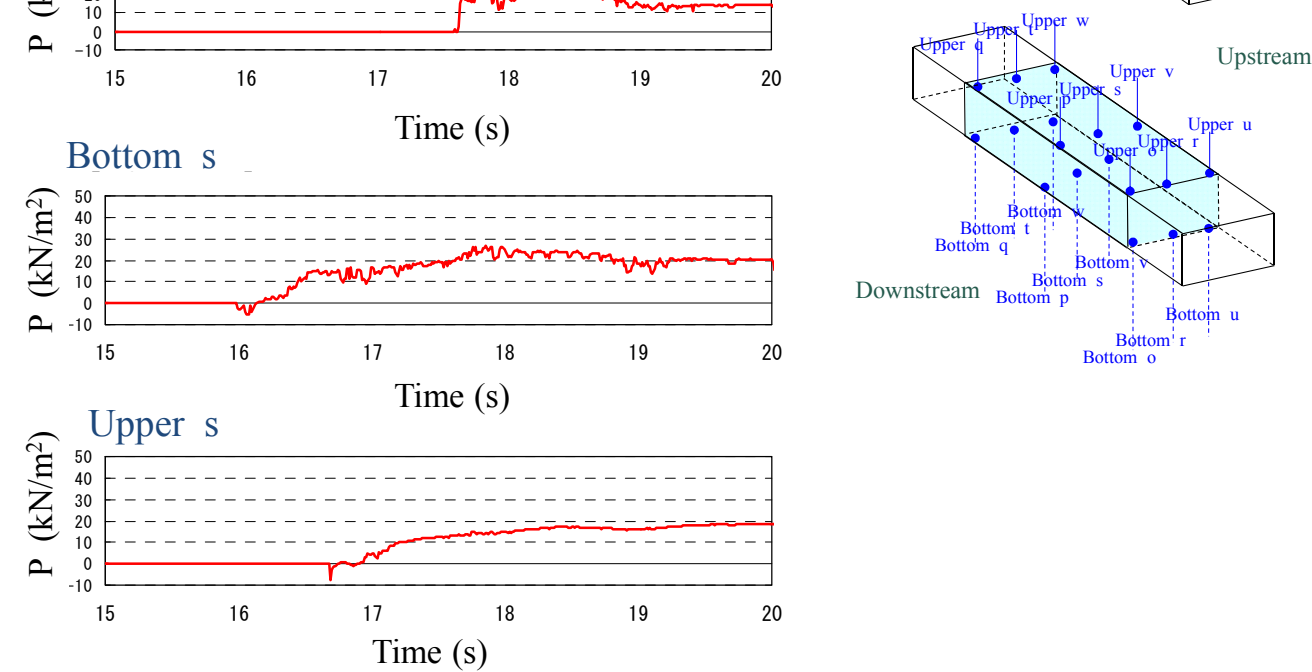

Figure 7. Time history of pressure acting on the center of front, rear, upper, and bottom face.

\section{CONFIRMATION OF NUMERICAL RESULT BY HYDRAULIC EXPERIMENT}

Hydraulic experiment was conducted in order to confirm the validity of numerical results. This study used a flat open channel with $12 \mathrm{~m}$ in length, $0.6 \mathrm{~m}$ in height and $0.4 \mathrm{~m}$ in depth. Fig. 8 shows the configuration of experiment. The model scale was assumed $1 / 50$. The experiment was conducted under the condition with and without an adjacent highway bridge. Some pressure gages were attached on the face of the model bridge, and output signal was recorded with $500 \mathrm{~Hz}$ sampling frequency. Water depth on the upstream side of the gate was set from $0.2 \mathrm{~m}$ to $0.3 \mathrm{~m}$, and the water depth on the downstream side of the gate was maintained as $0.02 \mathrm{~m}$. Under these conditions, bore type tsunami was generated by lifting up the gate quickly. In numerical simulation, the same configurations, such as the size of open channel, bridge model and water depth, were set in CADMAS-SURF/3D.

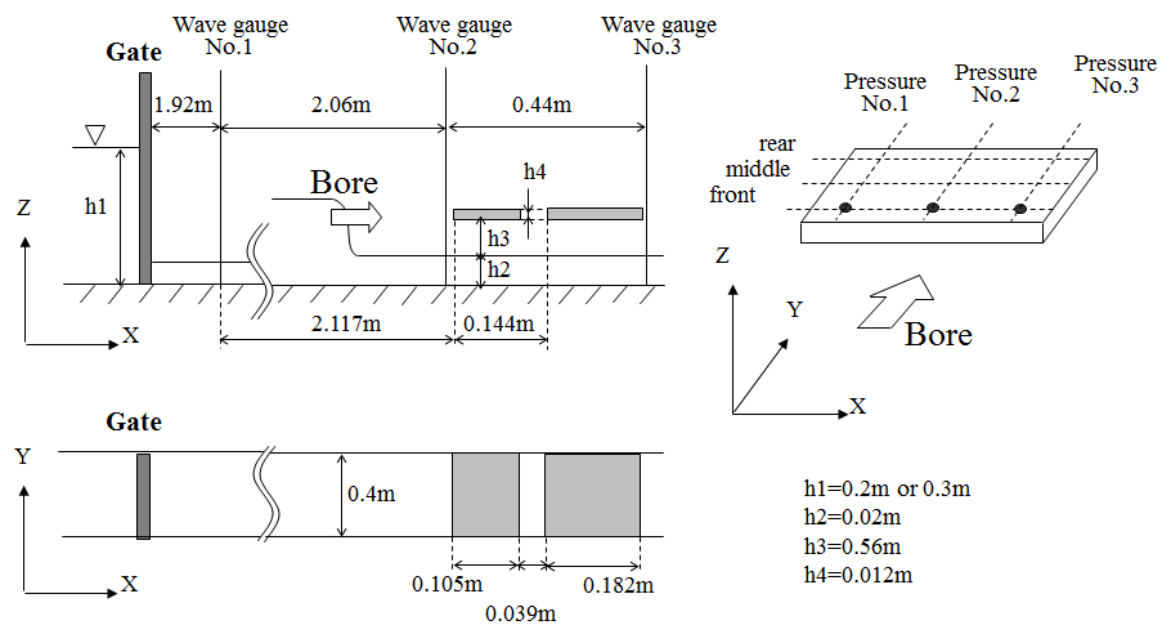

Figure 8. Configuration of hydraulic experiment. 
Fig.9 shows the comparison of wave pressure acting on the bottom face of the slab. As a reference, the result of the case without adjacent highway bridge is shown in this figure. This study confirmed that the pressure profiles on the slab obtained from numerical simulation show fairly good agreement with the results obtained from hydraulic experiment. In some cases, however, the small difference can be seen at the beginning of pressure increase as shown in Fig.9 (b). Front face of the bore type tsunami includes grate amount of air, and the repeatability of phenomena in hydraulic experiment was assumed one of the reason of above difference.

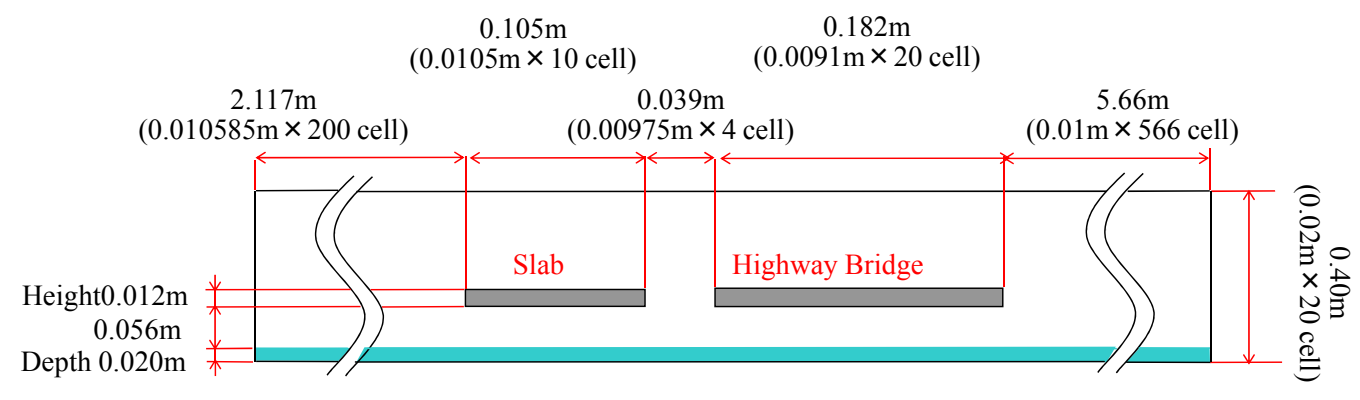

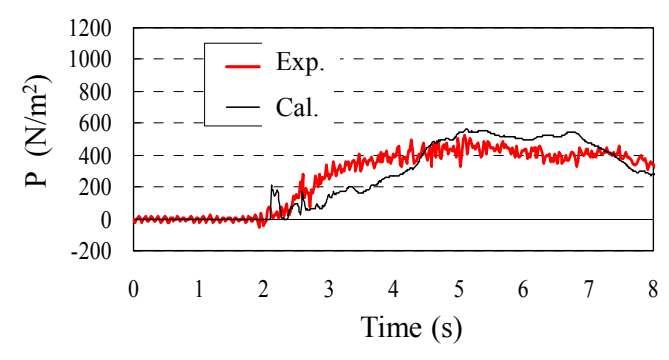

(a) With highway bridge

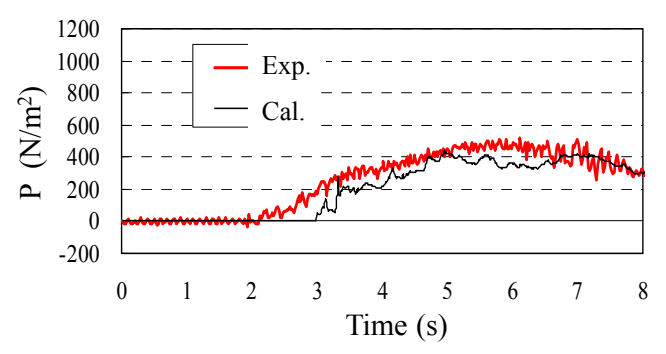

(b) Without highway bridge

Figure 9. Comparison of the bottom pressure between numerical result and experimental one.

\section{STRUCTURAL ANALYSIS OF DAMAGED SLAB BRIDGE}

Structural analysis is conducted by introducing Fiber model (Nonaka et al., 2010). This model can simulate elasto-plastic system. The configuration of this model is shown in Fig.10. Fiber element was applied on the slab section. Bearing capacity at each support section was also modeled by introducing a spring model. In Fiber model, the slab was divided into 50 elements in horizontal direction, and 5 elements in vertical direction. Wave forces acting on the slab faces on each time step were applied on each computational node which was arranged on the element as shown in Fig.10.
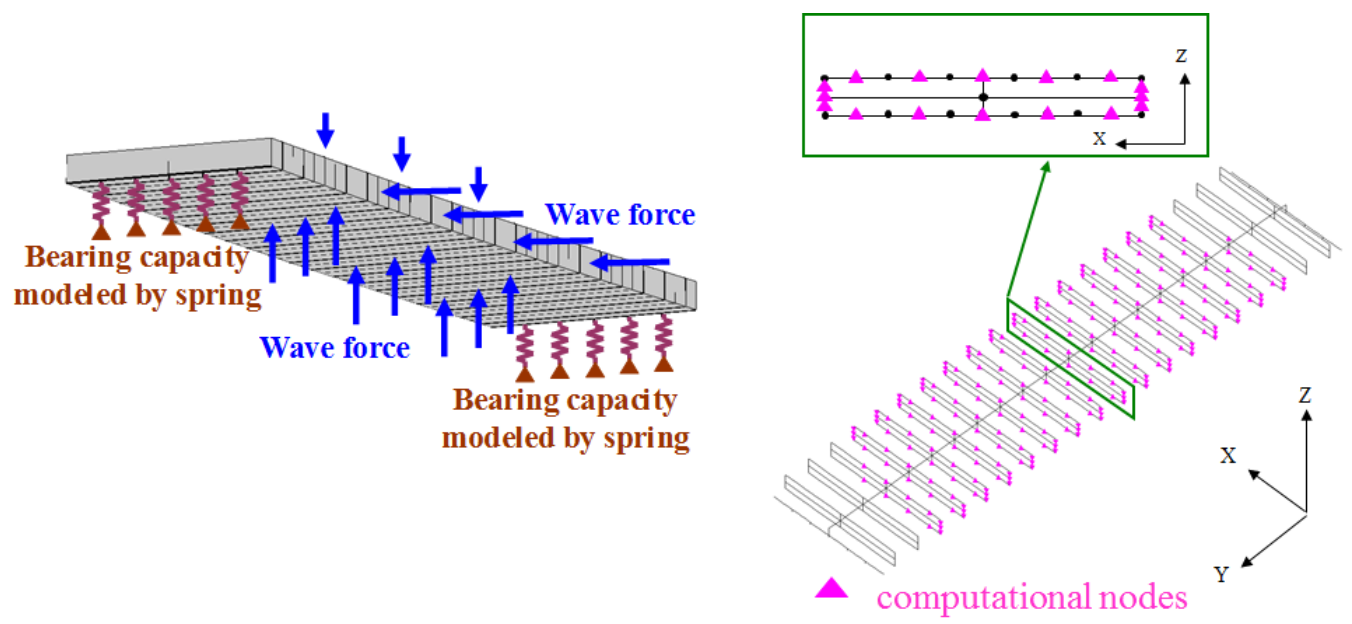

Figure 10. Model of structural analysis based on Fiber model. 
Fig.11 shows some examples of wave force profile applied on a computational node in structural analysis. These forces were obtained from the result of hydraulic analysis mentioned in the previous section. As shown in Fig.9, pressure profiles include small fluctuation due to complex phenomena under tsunami action. Those fluctuations were seemed negligible in structural analysis and smoothed by using running average. In Fig.11, the positive force acting on front and rear section means the force which floods the slab to the same direction as tsunami propagation. Also, the positive force on bottom and upper section means the force which uplifts the slab.
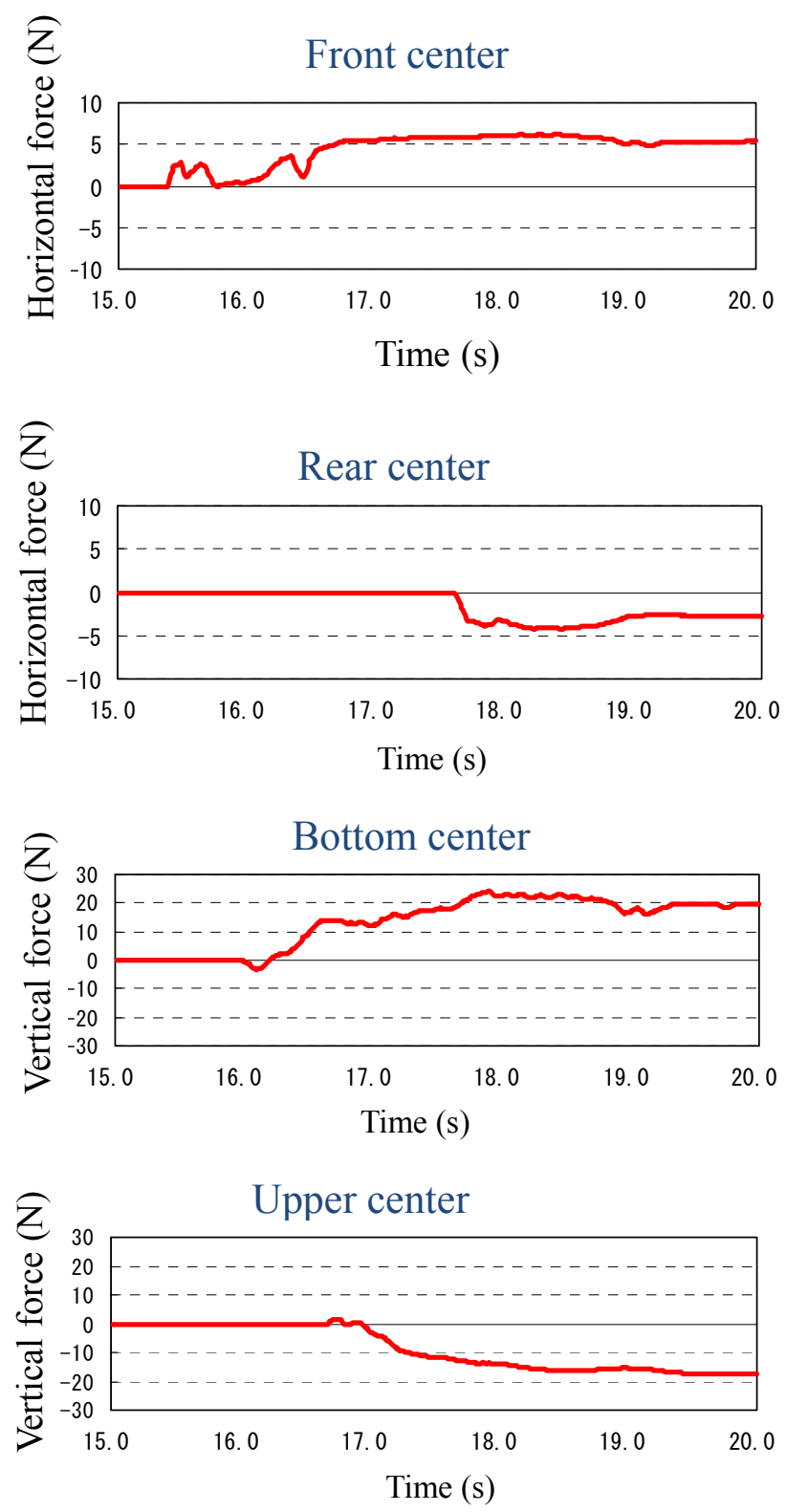

Figure 11. Examples of wave force applied on a computational node in structural analysis.

There are five anchor bars on both bearing section of the flooded bridge. Fig.12 shows the vertical reaction force at the anchor bar No.5 during tsunami action, where the No.5 is the most seaside anchor bar. The vertical reaction is normalized by the dead load of the slab, and negative value in these figures means an uplift force. The numerical simulation revealed that the uplift force acted at the anchor bars from No. 3 to No. 5 during tsunami action. This result means that the seaside section of the slab was lifted at first, and the slab was flooded onto the adjacent highway bridge with counterclockwise rotation during tsunami action as shown in Fig.13. 


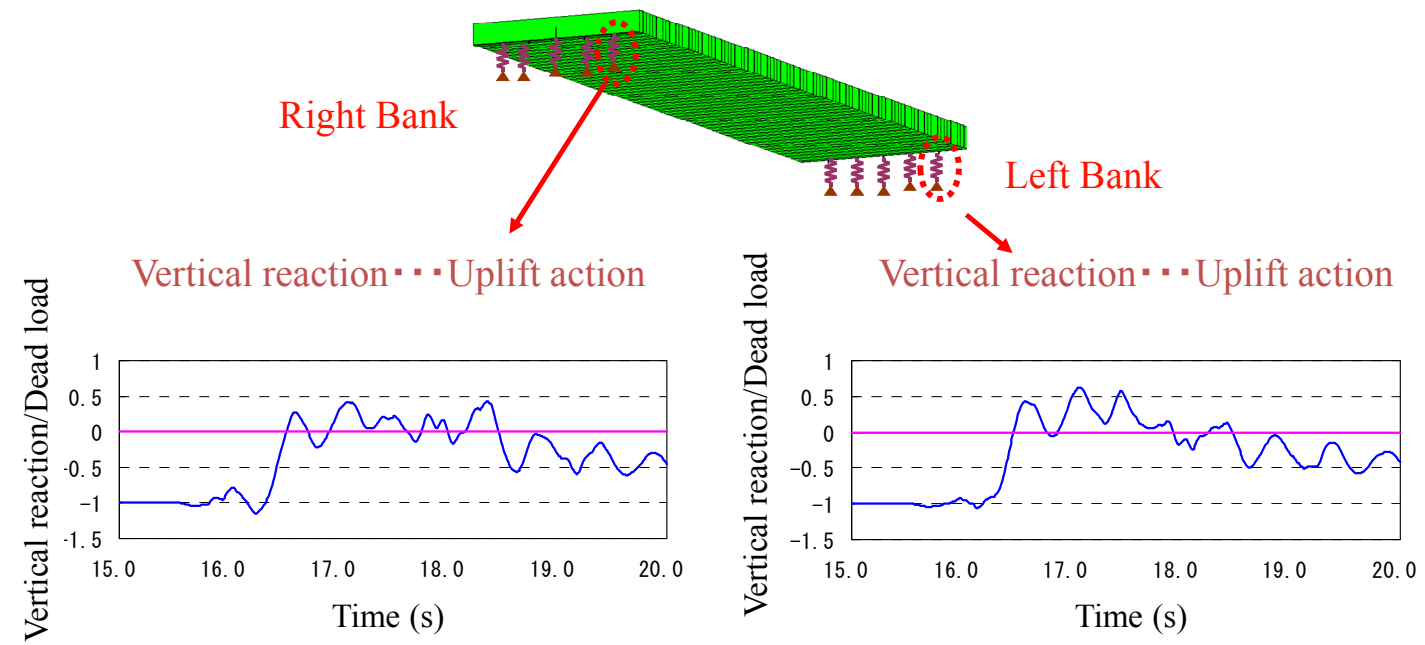

Figure 12. Vertical forces act on the bearing section at No.5 anchor bar.

On the other hand, the horizontal force acted on the slab was smaller than the vertical uplift force. Judging from the configuration of common slab bridge, this horizontal force also seems smaller than a yield stress. However, the damage of some anchor bars, which support the horizontal force, was observed after the slab section was flooded due to tsunami attack. As mentioned in above paragraph, the structural analysis showed that the seaside section of the slab was lifted and the slab turned with counterclockwise rotation during tsunami action as shown in Fig.13. Under this condition, only the anchor bars of No.1 and No2 support the flooding slab, because the seaside section of the slab was lifted upward, and anchor bars from No.3 to No.5 could not work as a bearing section. The number of effective anchor bars decreased during tsunami action, and it caused the damage of anchor bars at No.1 and No.2 which were bended to the landward as shown in Fig.2.

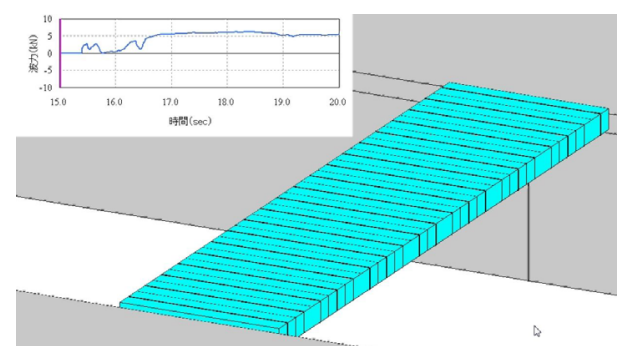

(a) $t=0$ sec.

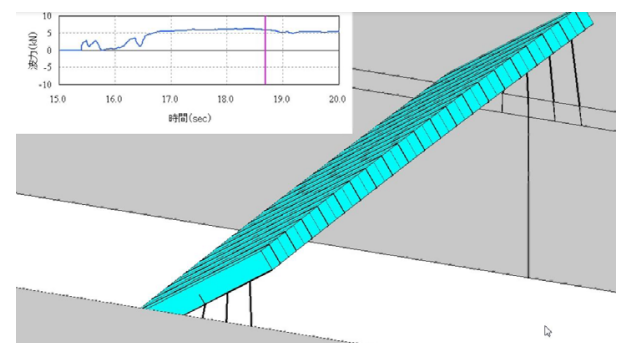

(b) $t=17.3 \mathrm{sec}$.

Figure 13. Motion of the slab during tsunami action

\section{CONCLUSIONS}

This study proposed a composite simulation method in order to investigate the mechanism of damage on the superstructure of bridges caused by tsunami. The numerical method consists of hydraulic analysis and structural one. This study employed Cadmas-Surf/3D in hydraulic analysis, and also employed EERC/Fiber which can simulate elasto-plastic system with Fiber model. The validity of numerical results obtained from Cadmas-Surf/3D was checked by hydraulic experiment. This study confirmed that the computed tsunami pressures on the slab show fairly good agreement with measured ones.

This study also discussed the mechanism of damage on the superstructure of bridge through structural analysis. The structural analysis was conducted by applying the time history of tsunami pressure on the slab, where the pressure was obtained from hydraulic analysis. The structural analysis revealed that the uplift force acted at anchor bars from No.3 to No.5 during tsunami action. From the investigation of reactions at each anchor bar, it was assumed that the seaside section of the slab was lifted at first, and the slab was flooded onto the adjacent highway bridge with counterclockwise rotation during tsunami action. 
In this study, the horizontal force acting on the investigated slab seems smaller than a yield stress. However, the damage of some anchor bars at No.1 and No.2 was observed after the slab was flooded due to tsunami. The structural analysis revealed that only the anchor bars at No.1 and No2 support the slab, and the anchor bars from No.3 to No.5 could not work as a bearing section because the seaside section of the slab was lifted up with counterclockwise rotation. The number of effective anchor bars decreased during tsunami action, and it caused the damage of some anchor bars.

\section{REFERENCES}

Araki S., Sakashita Y., and I. Deguchi. 2010. Characteristics of horizontal and vertical tsunami force on bridge beam, Journal of Japan Society of Civil Engineering, B2,Vol.66, No.1, JSCE, 796-800.

Nakao N., Murakami S., Izuno K., and K. Kobayashi. 2010. Experimental study on hydrodynamic force acting on bridges with small number of main girder under tsunami action, Proceedings of $13^{\text {th }}$ symposium on ducting design method for bridges, JSCE, 103-108.

Nii S., Kousa K., Miyahara K., and M. Shouji. 2009. Discrete element analysis for tsunami damages on bridges with considering parameters of tsunami height and girder height, Proceedings of $12^{\text {th }}$ symposium on ducting design method for bridges, JSCE, 69-74.

Nii S., Kousa K., Miyahara K., and M. Shouji. 2010. Study on proposal of estimation method of tsunami force on bridges and safety verification method based on experimental results, Proceedings of $13^{\text {th }}$ symposium on ducting design method for bridges, JSCE, 109-116.

Fukui Y., Shiraishi H., Nakamura M., and Y. Sasaki. 1962. Study on tsunami (I) - about celerity of bore tsunami-, Proceedings of $9^{\text {th }}$ coastal Engineering, JSCE, 44-49.

Nonaka T., and K. Yoshino. 2010. Elasto-Plastic analysis based on Fiber model for personal computer, Maruzen, $216 \mathrm{pp}$.

Coastal Development Institute of Technology. 2010. CADMAS-SURF/3D Research and development of numerical wave tank, Coastal Technology Library, No.39, 235 pp. 